\title{
Interactive comment on "Hydrogeomorphological analysis and modelling for a comprehensive understanding of flash-flood damaging processes: The 9th October 2018 event in North-eastern Mallorca" by Joan Estrany et al.
}

Joan Estrany et al.

joan.estrany@uib.cat

Received and published: 20 May 2020

RC2 - Anonymous Referee \#2 Received and published: 3 February 2020 SUMMARY: This manuscript analyses a flash flood event in a small catchment in the North-Eastern part of the Spanish Island of Mallorca, that left 13 people dead and caused severe damages to local properties. The analysis looks into four main aspects of the event, namely the meteorological conditions, the hydrological and hydraulic response, the damage assessment and a geomorphological analysis with the aim to improve the understanding of the drivers of this respective event. The authors conducted field measurements

Printer-friendly version

Discussion paper 
on the geomorphology few days after the event and present those findings alongside measurements of the rainfall, discharge and a damage assessment of a severely hit village in the catchment based on ground-based records and remote sensing information. The authors use hydraulic and hydrologic models to model the runoff processes in the catchment. The presented data and results are discussed by topic and summarized in the conclusion.

Interactive

comment

We are very grateful by the accurate summary provided by the reviewer.

GENERAL COMMENTS: The paper is very interesting to read and provides important information on frequently underreported local flash flood events. The four aspects of the event are presented in great detail with very detailed information on the technical background of the data collection and modelling. The authors kindly appreciate the comments from Reviewer\#2, which have helped to improve the MS.

However, overall the paper appears very fragmented with little connection between the different analysis. From reading the paper I was not able to fully understand how the presented data sets and models relate to each other and what are the main conclusions from the analysis. While the authors claim that their study uses an "[...] integrated approach with meteorological, hydrological, geomorphological, damage and risk data analysis" (L616f), the different analysis are presented largely isolated and independent including the discussion. Here, it would help if the authors would A) provide an overview figure that shows how the data sets and models are linked and B) A joint discussion that highlights how the individual results are linked and how this contributes to a better understanding of what made the event so devastating.

We agree with the Anonymous Referee \#2 comments, which are -at the same time- fitted with some of the concerns highlighted by the Anonymous Referee \#1. We are also very pleased to the referee for providing constructive ideas that -we believe- have improved the new version of the MS. Accordingly, also applying a suggestion provided by the Anonymous Referee \#1, we have created an overview figure showing the links be-

Printer-friendly version

Discussion paper 
tween data and models. It is the new Figure 1. The Discussion section has also been completely restructured without subsections to facilitate the combination of the individual results contributing to an integrated comprehension of the devastation. Firstly, the two subsections have been unified forming a unique storyline where hydrological response, rainfall-runoff modelling, damage assessment and geomorphic change are integrated. We believe this new version of the MS is bridging the gap between them, because we have introduced several paragraphs especially focused on the predictability of this kind of flash-flood events in order to better join these different issues. In addition, the new Figure 1 is also useful to better understand the integrated approach. Secondly, we have addressed a qualitative -but also quantitative-discussion about the role played by rainfall intensity and its spatial distribution, complex geology and land cover disturbances, following the suggestion provided by the Anonymous Referee 1\#. For this purpose, we have also modified the subsection 2.1. Study area (see Lines 178190 of the revised MS), where a deeper assessment of permeability in lithology materials as well as a diachronic evaluation of land uses evolution and perturbations (i.e., wildfires) is sustaining the discussion on the role of physical parameters generating the flash flood (see Lines 178-190 of the revised MS): "The lithology is mainly composed of marls intercalated with limestone $(60 \%$ of the area) of the Medium-Upper Jurassic (Dogger), dolomites (22\% of the area) of the Upper Triassic and Lower Jurassic, and pelagic limestone marls (14\% of the area) of the Lower Cretaceous (Fig. 2d). This lithological composition determines the surface water/groundwater interaction. On the one hand, a high degree of fracturing, fissuring and karstification of limestone favours percolation through karstic aquifers. On the other hand, the imperviousness of Dogger and Cretaceous marls ( $74 \%$ of the area) does not allow percolation, enabling runoff generation. The main land use in 2012 was agriculture (58\%), mostly located in lowland areas. Forest $(26 \%)$ and scrubland (17\%) were predominant at headwaters. Terraced fields still occupied $10 \%$ of the catchment, although most of them were abandoned (Fig. 2e). In 1956, natural vegetation covered $21 \%$ of the catchment. This rose to $42 \%$ in 2012 due to an afforestation process of former agricultural land in the second half of

Printer-friendly version Discussion paper 
the twentieth century. In combination with other factors, afforestation triggered a higher fire risk: two wildfires burnt an area of $1.7 \mathrm{~km} 2$ : 17\% in 1983 and 83\% in 2011 (Balearic Forestry and Soil Conservation Service, http://xarxaforestal.caib.es; Fig. 2e)".

We have also placed special emphasis on the sudden increase in discharge from 120 to $442 \mathrm{~m} 3 \mathrm{~s}-1$, which has resulted from the combination of all these physical parameters. Please, see the Lines 675-703 of the revised MS: "This runoff response resulted from the combination of rainfall intensity and its spatial distribution, complex geology and land cover disturbances in generating a high Qpeak (i.e., $442 \mathrm{m3}$ s-1) with high potential for generating geomorphological changes. Thus, the Qpeak unit obtained (i.e., $19 \mathrm{~m} 3 \mathrm{~s}-1 \mathrm{~km} 2$ ) can be classified as the third highest value of all the reported values in Marchi et al. (2010) and the highest of those values obtained from streamflow measurements in a hydrometric station and not by post-event analysis. The hydrologic response analysis in the course of a flash flood shows how storm structure and evolution result in a scale-dependent flood response (Borga et al., 2007). Consequently, spatial rainfall organisation, geology combined with orography and land cover disturbances led to pronounced contrasts in the flood response at the Begura de Salma River. Spatial rainfall on the catchment scale showed that the highest accumulation at the beginning of the storm was located at the headwaters of the catchment (at 15:00 h), whilst during the last part of the event the most important rainfall amounts were located in the downstream part. Examination of the flood response illustrated how the extent and the position of the karst terrain (Zanon et al., 2010) and soil conservation practices (Calsamiglia et al., 2018; Tarolli et al., 2014) provided major geological and anthropogenic control of runoff response. Impervious materials cover $74 \%$ of the Begura de Salma River catchment, mostly located at the headwaters, which are responsible for the highest values of topographic torrentiality (Estrany and Grimalt, 2014b), facilitating rapid overland flow generation. During the first part of the storm, when the highest rainfall amounts affected the headwaters, runoff response was delayed by the laminar effect of check-dam terraces massively constructed over Cretaceous marls (Calvo-Cases et al., 2020) and by the predominance of percolation in those areas covered by limestone,

Interactive comment
Printer-friendly version

Discussion paper 
mostly in the intermediate parts of the catchment. During the last part of the event, when the highest rainfall intensities were in the downstream part, the excess of soil infiltration capacity and the collapse of headwater check-dam structures triggered the sudden increase in discharge from 120 to $442 \mathrm{~m} 3 \mathrm{~s}-1$ in only15 minutes at the hydrometric station. Moreover, the increase of $5 \mathrm{~km} 2(21 \%$ of the catchment area, see more details in section 2.1) of natural vegetation since the 1960s as a result of afforestation processes, increased fuel loads and the risk of wildfires led to $1.7 \mathrm{~km} 2(7 \%$ of the catchment) being burnt since 1980 . The removal of vegetation by fires has a similar effect (less interception, less soil storage), which has been experimentally documented after major fires. These factors are a major reason why the history of the steady devastation of plant cover in the Mediterranean is likely to enhance flood risk (Wainwright and Thornes, 2004) and increase desertification tendencies".

It also appears that there is quite a disconnect between the results, discussion and conclusion sections, where topics such as driving factors of the damage in urban areas are for the first time explicitly mentioned in the conclusions, while the previous chapters mainly focus on the methodological aspects of the damage assessments. Similarly, language and grammar vary considerably throughout the paper and rigorous copy editing is necessary prior to accepting the manuscript for publication. Given the otherwise interesting and very relevant contribution the paper makes in the field of flash flood post event studies, I recommend considering the manuscript for publication after major revisions.

We have tried to connct the different sections considering the driving factors of the damage. Likewise, we have unified the language and grammar also developing a deep review by a professional.

Specific comments Structure Introduction The introduction is very technical and has a very narrow focus on flash flood processes. It also appears to address a lot of specific subjects in no particular order rather then leading to the research questions the authors are aiming to answer. Restructuring the introduction so it clearly leads to the research

Printer-friendly version

Discussion paper 
questions and highlights the importance of the work would therefore really improve the quality of the paper. As this is not the first study of its kind, I would also recommend including a literature review on previous post event studies (both flash flood related and potentially other natural hazards) and their findings. This would give the reader the opportunity to better evaluate the contribution of the paper to the scientific discourse and what knowledge gaps it addresses.

Interactive

comment

We have modified the Introduction section amplifying the activating hydrological processes during a flash flood, including extra scientific literature on previous post event studies with a special emphasis on those analysing the role played by physical parameters in runoff generation in these catastrophic events (see Lines 54-69 of the revised MS): "Characterising the response of a catchment during an extreme flash-flood event is important because it clarifies flood severity and the activating hydrological processes and their dependency on natural and anthropogenic catchment properties (Borga et al., 2007). Numerous studies have tried to determine these driving factors (Braud et al., 2014), in which geological heterogeneities associated with the presence of karst features are crucial in Mediterranean catchments (Vannier et al., 2016; Wainwright and Thornes, 2004). Likewise, flash floods are closely related to land use: the devastation of plant cover in the Mediterranean may increase the risk of flooding because bare soil leads to larger runoff coefficients (Wainwright and Thornes, 2004). However, the limited spatial and temporal scales of flash floods make these events particularly difficult to monitor and document. In the case of rainfall monitoring, the spatial scales of the events are in general much smaller than the sampling potential offered by apparently dense rain networks (Borga et al., 2008; Amponsah et al., 2016). In the case of streamflow monitoring, there is a lack of flash-flood discharge $(Q)$ data from stream gauge observations (Marchi et al., 2010), although $Q$ data are crucial to obtaining representative hydrometric values and characterizing the runoff response of such extreme flash-flood events (Borga et al., 2008). As a result, further field observations and modelling studies are required in order to assess the interdependencies of flash-flood drivers and, thus, better understand and reproduce the active hydrological processes

Printer-friendly version

Discussion paper

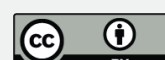


(Sofia and Nikolopoulos, 2020)".

Description of the study area For the sake of readability, I would recommend separating the meteorological conditions that lead to the event from the actual description of the study area.

We have created a new subsection, specifically entitled "2.2 Meteorological context of the 9th October 2018 rain event", being in the revised version of the MS completely separated from the Study area description, as follows: "2.2 Meteorological context of the 9th October 2018 rain event The 9th October storm affected the two northernmost catchments of the Llevant County; i.e., the Ca n'Amer and Canyamel Rivers (Fig. 2) with 9 and 4 casualties, respectively, and significant damage. The synoptic situation was like the situations generating flash-flood events in the Western Mediterranean (Fig. 3a). A cut-off low at mid-level was located in the eastern part of the Iberian Peninsula and shallow low-level pressure was affecting the same region, driving warm and wet air from the Mediterranean Sea to the Balearic Islands and the eastern part of the Iberian Peninsula. This occurred in early October, when the sea surface temperature is close to its annual maximum in the Western Mediterranean, providing high quantities of moisture. Moreover, the cut-off low showed a typical divergence at mid-level on its eastern flank, affecting the Balearic Islands and favouring the development of deep convection. Convection started on the sea between the Balearic Islands and the Iberian Peninsula (Figures $3 b$ and $3 c$ ) and, due to SW winds at mid-tropospheric levels, the convective cells started to move towards the Balearic Islands, where they triggered the flash-flood event after a heavy rainfall episode (Figures $3 \mathrm{~d}$ and $3 \mathrm{e}$ )".

Conclusion The conclusion appears to be quite detached from the rest of the manuscript addressing several points that have not been previously mentioned in the manuscript but are important to fully understand the analysis. For example, how the meteorological, hydrological, geomorphological, damage and risk data analysis are linked. Or what the actual damage driving factor in urban areas are based on the different findings.

Printer-friendly version

Discussion paper 
We believe that the modifications on the other sections are now helping to better understand those points that in the first version of the MS have not been previously mentioned. In the case of damage driving factors in the Sant Llorenç des Cardassar village, we have added some paragraphs in the Discussion sections, as follows (see Lines 742749 of the revised MS): "At present, Mallorca does not have any sort of early warning system to assist flood risk management, and nor of course has Sant Llorenç des Cardassar. Similarly, no hydrometeorological early warning was issued by the competent authorities, as the Balearic Islands have no operational hydrological control network releasing real-time information on discharges. In October 2018, Sant Llorenç des Cardassar was one of the four municipalities in Mallorca with a flood risk emergency plan. However, it was not operational at the time the emergency was declared. As a result, the population was completely unaware of how to defend themselves, even during the emergency phase, although Sant Llorenç des Cardassar municipality had significant social vulnerability to floods, as most of the casualties were tourists and the elderly".

Rainfall This paper focusses on the hydrological response as a main driver of the flash floods and the authors argue in the introduction that "the uncertainty in hydrological modelling can be large and hydrological models often need to be calibrated [...]. Therefore, the predictability of such events remain low also adding that predictability is lowered by a high non-linearity in the hydrological response related to threshold effects". This implies that the uncertainty in the hydrological models are a key barrier in the predictability of flash floods. However, most other studies on flash floods and flash flood early warning systems find the spatio-temporal uncertainties in the rainfall prediction to be the largest obstacle in accurately forecasting and modelling flash floods (see for example Alfieri et al. 2017). This issue is also addressed in the description of the rainfall data, but the authors do not report to what extend the results of the subsequent hydrological and hydraulic models are sensitive to the uncertainties of the rainfall input. Therefore, I would recommend adding a short sensitivity analysis in regard to the rainfall input to the discussion section. It would also be interesting to see to what extend the results vary between the radar and gauge data.

Interactive

comment

Printer-friendly version

Discussion paper 
We thank the reviewer on this very pertinent and interesting comment. We fully agree that the spatio-temporal uncertainty in the rainfall data is the main source of uncertainty in flash floods, an issue also commented by the Anonymous Referee \#1. We recognize that the text in our manuscript was misleading and we have accordingly modified the Introduction section (see Lines 76-78 of the revised MS): "The main source of uncertainty is related to the spatio-temporal scales of rainfall pattern. The forecasting of intense thunderstorms by numerical weather prediction systems to provide accurate rainfall information is particularly challenging (Alfieri et al., 2015; Collier, 2007)". Otherwise, the scientific issue aroused from this comment is very challenging. We believe that analysing the uncertainty sources of the hydrological model in this particular paper is out of scope, would mislead the reader also considering this topic would deserve a paper on its own. However, we have specifically minimized this uncertainty source by using a spatially interpolated rainfall from gauging stations in order to understand -from a modelling point of view- the processes leading to this event. It is clear that the estimated radar rainfall data used in our piece of work have provided a better spatial interpolation of the rainfall event than using only the radar data (see Fig. S1 and the Lines 265-270 in the subsection 2.3. Rainfall data of the revised MS). Moreover, the radar data was adjusted with data from San Llorenç des Cardassar station as described in this same supplementary figure (Fig. SF1) so that indirectly the rainfall data is already used in the model. Definitely, it would be interesting to further analyse the results of the uncalibrated radar data in these kind of extreme rain storms but it should be a future scientific work.

Risk management and early warning Given the high casualties and damage during this event it would be important to also cover the vulnerability of assets and people in the case study area for a comprehensive analysis of the damaging factors. This aspect however is only very briefly mentioned in the discussion and conclusion. Key questions would include: did people in the village receive some sort of early warning? Are their any risk management strategies in place apart from the mentioned flood zones? Discussing these aspects would also help to conclude with more specific recommen-

Printer-friendly version

Discussion paper 
dations for the improvement of risk management practises.

Nowadays, Mallorca Island does not have implemented any sort of early warning system to flood risk management, nor has the Sant Llorenç des Cardassar village. However, the Spanish Meteorological Agency (AEMET) applying the National Plan for the Observation of Adverse Meteorological Phenomena ("Meteoalerta"; http://www.aemet.es/en/lineas_de_interes/meteoalerta), forecasted storms and intense rains. On 9th October 2018 at 01:58 a.m., AEMET issued a yellow warning for rainfall amounts up to $20 \mathrm{~mm}$ in one hour in Balearic Islands, extending the duration of this warning until 12:00 p.m. on 10th October. At 6:53 p.m. on 9th October, the warning was raised to the orange level, $50 \mathrm{~mm}$ in one hour, in the east of Mallorca and in the north and northeast of Mallorca, and finally, at 10:07 p.m., reaching the red level, $220 \mathrm{~mm}$ in one hour, in the easternmost part of the north of Mallorca, being extended until 02:00 a.m. on 10th October. These different warnings clearly demonstrated that the storm was not well meteorological forecasted, due to both orange and red warnings were delivered when the disaster had already occurred. Likewise, no hydrometeorological early warning was issued by the competent authorities, also considering that the Balearic Islands do not have both an operational hydrological control network and real-time information on rainfall intensity through automatic weather stations in the headwaters of Begura de Salma River catchment. The municipality of Sant Llorenç des Cardassar was one of the four municipalities in Mallorca with municipal flood risk emergency plan, implemented previously to the catastrophe. However, it was not operational at the time the emergency was declared. The population was completely unaware of how to defend preventively themselves, even during the emergency phase. Regarding the social vulnerability, the Sant Llorenç des Cardassar municipality has 8,406 inhabitants, being $23 \%$ foreigners (IBESTAT, 2018). In addition, a very high tourist capacity including dispersed rural vacation homes; as well ageing population is $>16 \%$. All these variables increase the social vulnerability, a fact that has been proven due to the most of the casualties were tourists and ageing population during the catastrophe. As a result, any measure

Interactive comment
Printer-friendly version

Discussion paper 
to improve social vulnerability should be focused on increasing the knowledge of natural risks by foreign resident population and tourists. Almost two years after the catastrophe, its consequences have been applied as learnt lessons in preventing the risk. The City Council applying several actions (https://www.santllorenc.es/ca/noticiesajuntament/lajuntament-de-sant-llorenc-presenta-una-modificacio-puntual-del-seuplanejament-urbanistic-despres-de-la-torrentada-en-vista-a-millorar-la-seguretat-) such as significant modifications within the Urban Planning for reducing the exposed areas to flood risk in urbanized areas, multidisciplinary studies to improve knowledge of the population exposure level, and regulations to reduce the exposure of assets in the case of new flash floods. In addition, works on hydraulic infrastructures focused to restore the previous condition or even lowering the channel roughness, involving a risk increase. Despite population has more information on how to deal with possible new events, the implementation of a hydrometeorological alert system would be more effective, facilitating the monitoring of potential flash floods. We have refocused the Discussion section with several paragraphs in the Discussion section, as we have previously pointed out.

Damage classes In Figure 7(e), the distribution of the damage classes for the three different zones and the total of all zones are shown. It seems that the total does not correspond to the sum of the three zones as the by far largest group in total are houses being "Damaged \& Non habitable" with 260 houses, while the sum in this group for all three zones is 37 homes. That might be either an error or it should clearly be stated what is meant by "Total".

We must apologize by this mindless error caused by a mixing of cells in the Excel spreadsheet, although the explanation within the main text was correct. Certainly, "Damaged \& Non habitable" summed 37 for all three zones, not 260 houses. This 260 houses are "Damaged and habitable". We have pertinently modified in the new Figure 8e.

Sediment connectivity and geomorphic change While using the sediment connectiv-

Printer-friendly version

Discussion paper 11 
ity to support search and rescue missions after flash flood events is a very innovative approach, it is not entirely clear what one can learn from the sediment volume calculation. Discussing this number in the context of the other analysis and its implications for a better understanding of the flash flood processes would help to further improve the manuscript. It would also be interesting to learn what is the accuracy of the mentioned approach given the different spatial resolutions and accuracies between the 2014 and 2018 surface models. Can changes in volume attributed to this specific event or does this number also include other changes to the geomorphology (both human and natural) that happened between 2014 and 2018? I would also recommend to clearly separate the sediment connectivity analysis that was used to support the search and rescue efforts and the geomorphic change detection to make clear that the two analysis had different aims.

We must thank again to the referee for these relevant and appropriate questions, allowing an improvement of one of the key issues of our piece of work. In order to provide the necessary clearness to the readers about what are the real aims from both methods, we have split the methods subsection 2.6 Sediment connectivity and geomorphic change detection, being currently 2.6 Sediment connectivity and $2.7 \mathrm{Ge}-$ omorphic change detection. In addition, both methods in the new Figure 1 are also clearly separated, although also emphasizing their own relationship. We have modified the following sentence (see Lines 328-329 of the previous MS version): "Firstly, and taking into consideration the emergency situation, the index of (water and sediment) connectivity at the catchment scale was applied to find out the areas with the greatest sediment deposition potential where victims could have been buried by the flash flood". This is the new sentence (see Lines 407-409 of the revised MS), in which is better explaining the main aim of the IC implementation in terms of Emergency rescue tasks: "Firstly, and taking into account the emergency situation, the index of (water and sediment) connectivity at the catchment scale was applied to find the areas with the greatest sediment deposition potential, which were where victims could have been buried by the flash flood". Within the new subsection 2.7 Geomorphic change de-

Interactive comment
Printer-friendly version

Discussion paper 
tection, we have reinforced its main purpose in the first paragraph, as follows (see Lines 425-430 of the revised MS): "HR-DEMs facilitate the improvement of sediment connectivity as a powerful tool to determine preferential flow-paths and those areas with the greatest potential sediment deposition. The evaluation of the flash-flood landform signature by UAVs is the second part of creating a tool for a rapid response of post-catastrophe search and rescue tasks by applying hydrogeomorphological precision techniques. The estimation of overbank sedimentation allowed the calibration of the predicted large sedimentation by IC mapping and its reliability in detecting sites where victims might be buried by flood sediment". In order to clarify that no changes in volume occurred between 2014 and 2018, we have added a new sentence in the new subsection 2.7 (see Lines 459-461 of the revised MS): "It is worth noting that no geomorphic changes were observed between 2014 and October 2018 by photointerpretation of aerial imagery (PNOA, 2015) and the continuous measurement of water stages since January 2015, with no overbanked flood events". Finally, the accuracy of the approach was settled, as mentioned in the first MS version, by an assessment of RMSE in xyz. However, we have reinforced this method adding "and located on surfaces not modified by the flash flood".

Additional comments As mentioned earlier, the manuscript would benefit from English language copy editing. Instead of giving point-by-point corrections I would like to provide a a few examples, which I find difficult to understand:

The authors we are grateful with detailed suggestions on English language and grammar. Following this advice, we have requested an external review on English language by a professional native speaker (see attached the certificate).

L 51f: "Characterising the response of a catchment during flash flood events is important because elucidate the hydrological processes from an extreme flood and their dependency on catchment properties and flood severity (Borga et al., 2007)" should probably be: "Characterising the response of a catchment during flash flood events is important because it helps understanding the hydrological processes of extreme floods

Printer-friendly version

Discussion paper 
and their dependency in regard to the properties of the catchment and the severity of the event."

The Anonymous Referee \#1 had also suggested a change in English language style within the sentence.

L 112f: "[...] was developed affording the analysis of the rainfall-runoff processes at small spatial scale during this extreme event." I did not understand what "affording" means in this context.

We have changed "affording" by "through".

L125: "high-energy environment" I did not understand what "high-energy" means in this context

We believe that "high-energy environment" is a concept completely accepted in the argot of Earth sciences and is comprehensible in the context developed within this sentence. However, we have modified the beginning of the sentence including the geographical context: "In such a high-energy environment,...".

L156: "under a recurrent affection of wildfires": does that mean that these areas are regularly affected by wildfires or that these areas are prone to wildfires?

These areas are both prone to wildfires and have been affected by wildfires twice in the last 30 years. In addition, one of the main concerns provided by both referees are related with the physical processes conditioning the hydrological response of the flash flood event. In this way, we have improved the description of the subsection 2.1. Study area in order to better contextualize the influence of lithology, land uses and wildfires in the hydrological response during the extreme flash flood event (see Lines 178-190 of the revised MS): "The lithology is mainly composed of marls intercalated with limestone (60\% of the area) of the Medium-Upper Jurassic (Dogger), dolomites (22\% of the area) of the Upper Triassic and Lower Jurassic, and pelagic limestone marls (14\% of the area) of the Lower Cretaceous (Fig. 2d). This lithological composition determines the

Printer-friendly version

Discussion paper 
surface water/groundwater interaction. On the one hand, a high degree of fracturing, fissuring and karstification of limestone favours percolation through karstic aquifers. On the other hand, the imperviousness of Dogger and Cretaceous marls (74\% of the area) does not allow percolation, enabling runoff generation. The main land use in 2012 was agriculture (58\%), mostly located in lowland areas. Forest (26\%) and scrubland (17\%) were predominant at headwaters. Terraced fields still occupied $10 \%$ of the catchment, although most of them were abandoned (Fig. 2e). In 1956, natural vegetation covered $21 \%$ of the catchment. This rose to $42 \%$ in 2012 due to an afforestation process of former agricultural land in the second half of the twentieth century. In combination with other factors, afforestation triggered a higher fire risk: two wildfires burnt an area of 1.7 km2: 17\% in 1983 and 83\% in 2011 (Balearic Forestry and Soil Conservation Service, http://xarxaforestal.caib.es; Fig. 2e)".

Interactive comment on Nat. Hazards Earth Syst. Sci. Discuss., https://doi.org/10.5194/nhess2019-304, 2019.

Printer-friendly version

Discussion paper 


\section{NHESSD}

Interactive

comment

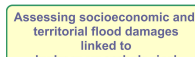

Aerritorial finkod do do
linges
hydrogeomorphologien

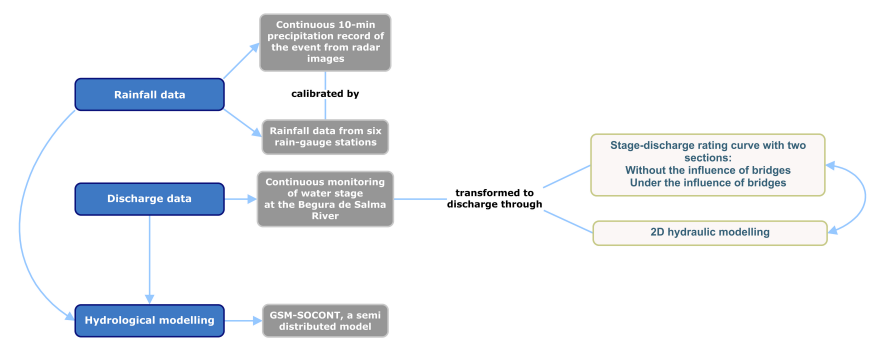

Reproducing the flashy
hydrological

hydrological
sumse of the catchment

Hydrological modelling

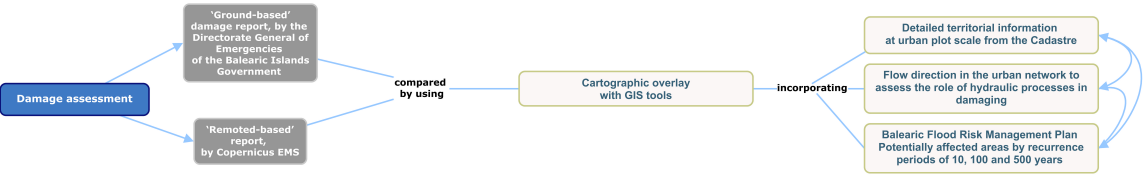

Investigating a tool for a rapid
ressonse

post-catastrophe search and
rescue tasks

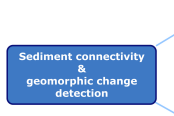

The sediment
connectivity index (IC)

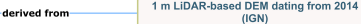

to find out - Areas with the greatest potential sediment
deposition

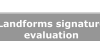

0.05 m-UAV-based DEM dating
from six days after the catastrophe
(MEDhyCON)

Amount of overbank sodimentation in the
area of the resecue where 1 c c suggested the

Fig. 1. Figure 1. Workflow of the experimental design. 


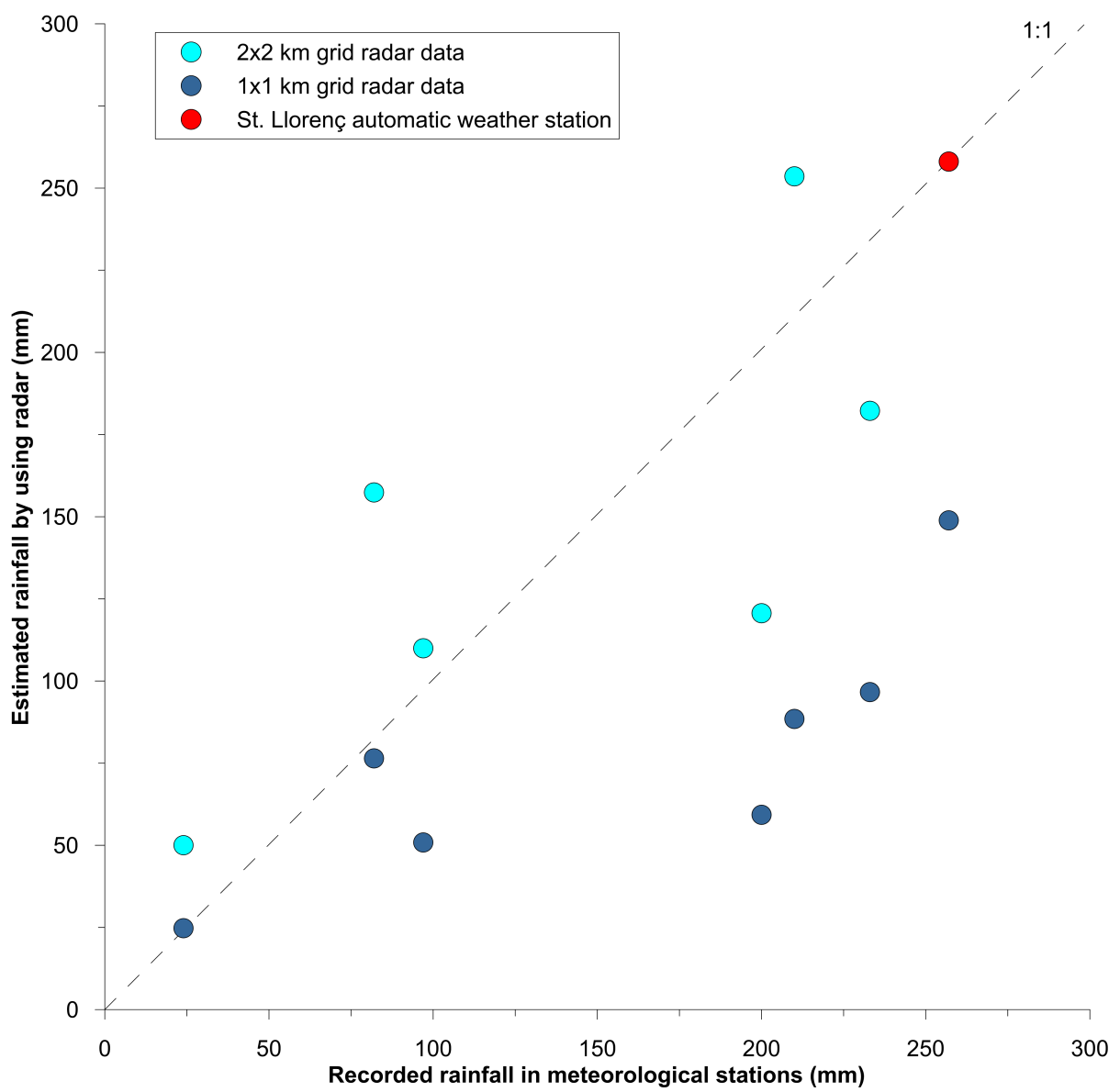

NHESSD

Interactive

comment

Printer-friendly version

Fig. 2. Figure S2. Scatterplot of recorded rainfall in meteorological stations and estimated

Discussion paper rainfall by using different grid radar. 

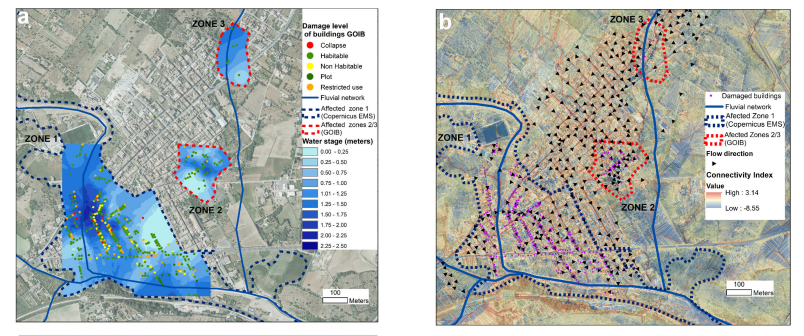

\section{NHESSD}

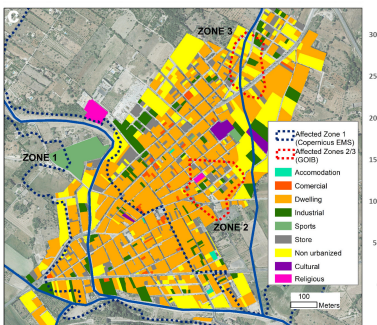

\section{d}

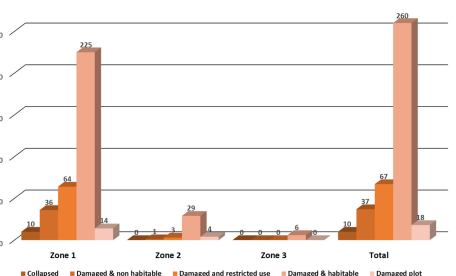

Interactive

comment

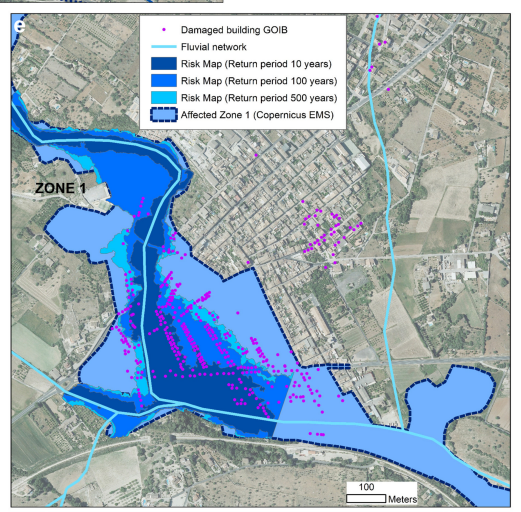

Fig. 3. Figure 8 (a) Map of the damage level classification of buildings and water stage reached in the different affected zones at Sant Llorenç des Cardassar according to the Balearic Islands Autonomous Gove 